\title{
El amor cristiano de Heraclio
}

\section{Q María Cristina Silventi}

Universidad Nacional de Cuyo, Argentina

silventicris@gmail.com

Recibido: 9/6/2018. Aceptado: 16/11/2018.

\section{Resumen}

A través de la mayor parte de las composiciones de Jorge de Pisidia (c.589-634) conocemos las campañas llevadas a cabo por el emperador Heraclio (610-641) contra los persas. El poeta toma los hechos históricos y les da trascendencia religiosa. Heraclio es presentado como el líder cristiano, que fortalecido por la fe, se manifiesta ante sus hombres como verdadero testimonio del amor cristiano. Jorge de Pisidia resalta entre sus cualidades, la claridad y serenidad de pensamiento, las acciones ejemplares y el poder persuasivo de su palabra que ejerce una poderosa influencia sobre sus hombres.

\section{The Christian love of Heraclius}

\begin{abstract}
Through most of George Pisides's compositions (c. 589-634) we know the campaigns carried out by the Emperor Heraclius (610-641) against the Persians. The poet takes historical facts and gives them religious significance. Heraclius is presented as the Christian leader, who strengthened by faith, manifests himself before his men as a true witness of Christian love. George Pisides highlights among its qualities, clarity and serenity of thought, exemplary actions and the persuasive power of his word that exercises a powerful influence on his men.
\end{abstract}

El presente trabajo intenta demostrar, a través de la selección de algunos versos del poema breve Por el retorno desde África del emperador Heraclio y su ascenso al trono y contra el emperador Focas y de Expediciones Pérsicas, que las cualidades

\section{Palabras clave}

Jorge de Pisidia Expediciones Pérsicas Heraclio

\section{Keywords}

George Pisides Expeditio Persica Heraclius 
1. La adopción del título basileus relacionado con la 'liturgification' de la ceremonia de la corte, enfatizando el origen divino de Heraclio y su misión religiosa es resaltado como principal motivo por algunos investigadores, cfr. Haldon (2002:1-16); Riveros (2011:60). Para otros investigadores aún continúa la discusión al respecto, cfr. Brandes (2002:19). Heraclio como "first crusader" cfr. Regan (2001:77); Soto Chica (2005:681); Serrano del Pozo (2018:89); Laurent (1939:355). Según Pertusi (1959:249) Jorge de Pisidia en Heraclias es presentado como "condottiero" de Dios. Heraclio como "eschatological emperor" cfr. Queiroz de Souza (2015:27-38). Respecto de la paulatina helenización de la lengua hablada y luego de la escrita, así como en lo administrativo, cfr. López Cruces; Papadopoulou (2017:468-470); Brandes (2002:19); Soto Chica (2012:252-262). resaltadas por el poeta, Jorge de Pisidia, respecto del emperador (autokrátor) Heraclio (610-641), se encuentran poéticamente enlazadas por el amor cristiano.

La figura de Flavio Heraclio Augusto (c. 575-641 d.C.), emperador de los romanos entre los años 610 y 641 d.C. se constituyó en símbolo religioso desde su época hasta nuestros días. Consciente de la trascendencia de sus actos, adoptó el nombre oficial de basileus para presentarse ante su pueblo como el nuevo rey designado por Dios. Al respecto afirma Vasiliev:

Tras el feliz desenlace de la guerra persa, Heraclio, en 629, tomó por primera vez el nombre oficial de basileo. Tal nombre existía hacía siglos en Oriente, y sobre todo en Egipto, y desde el siglo IV habíase hecho corriente en las zonas de lengua griega del imperio, pero sin ser reconocido todavía como título oficial. Hasta el siglo VII, el equivalente griego del latino imperator, había sido la palabra autokrátor, es decir, "autócrata", que etimológicamente no correspondía al sentido de imperator. (Gómez; Brenates, 2004:112)

También Castillo Fasoli resalta este cambio de denominación, cuando habla de las modificaciones realizadas por Heraclio en lo concerniente a la administración:

Heraclio helenizó gran parte de la administración, aclimatándola al pueblo, que ya no hablaba latín, sino griego, ejemplo que fuera seguido por sus sucesores hasta la helenización de las leyes por León III. Por ejemplo, rehusó el título romano de imperator, adoptando el griego de basileus (Castillo Fasoli, 2009:87). ${ }^{1}$

El retrato que configura el poeta a través del relato de sus hazañas destaca la profunda convicción religiosa de su mecenas, cuyo desempeño es resultado de la inspiración divina (cfr. Whitby, 1998:263):

The war ahead was no longer seen as merely a continuation of the territorial disputes that had characterized Romano-Persian relations for many centuries. It became part of the eternal struggle between God and Evil, with the Sasanian king Khusro cast a Satan, enemy of God. The poet and court chronicler George of Pisidia described Heraclius (his paymaster, of course) as the instrument chosen by God to punish the evil-doers, the fire-worshipping Persians. Like the biblical David, Heraclius was the man God had chosen to lead the Romans -now the chosen people-in their struggle to regain Jerusalem and the True Cross (Regan, 2001:70).

Heraclio, desde que asumió el poder buscó recuperar la obra de Constantino (270 y 288-337), que había institucionalizado un imperio cuyas estructuras se asentaban en una población cristiana y un emperador considerado representante e intérprete directo de la voluntad divina.

Consciente de la trascendencia de este emperador, Heraclio adoptó el mismo régimen de vida que caracterizó a Constantino. Eusebio de Cesarea en su Vida de Constantino exalta su figura como el ideal del gobernante cristiano:

[...] Dios en cambio, que es uno y único, al atrincherar a su siervo, él solo frente a todos, con toda la armadura divina, y al purgar por su intermedio la vida humana de esa masa de ateos, hizo de él para todos los pueblos, un maestro de piedad hacia sí mismo, un maestro que a plena voz testifica a todos los oídos que él conoce al que es Dios, y que vuelve la espalda al desvarío de los que en modo alguno lo son. Eso es lo que él ponía en práctica y proclamaba, como leal y buen servidor, declarándose sin paliativos esclavo, y reconociéndose siervo del soberano universal (Gurruchaga, 1994:145-146). 
Fiel a esta vocación entró en las páginas de la historia de Oriente a través de los versos de Jorge de Pisidia. Gracias a este poeta conocemos que Heraclio realizó importantes campañas para recuperar las provincias orientales, terminar con la amenaza de los ávaros en Occidente y extender su imperio en ambas direcciones. Sus hazañas son exaltadas remarcando en ellas las cualidades espirituales que le permitieron trascender como leyenda más allá de su tiempo. ${ }^{2}$ Soto Chica (2017:261) lo reconoce como "el mejor exponente del nuevo héroe bizantino [...]. El emperador heroico por excelencia". También McGuckin (2011-2012:40-41) destaca la importancia de Heraclio como partícipe activo de la convicción de que Bizancio estaba involucrada en una guerra santa. De hecho, la recuperación de la cruz fue la ocasión para crear un importante festival que adaptó la antigua fiesta de Constantino, fiesta celebrada el 14 de setiembre y desde entonces fue una experiencia litúrgica fundamental que trascendió su época y en torno a la cual la teología ortodoxa fundamentaría sus valores patrióticos.

Teniendo presente el fragmento anterior sobre la personalidad de Constantino y las obras de Jorge de Pisidia anteriormente citadas, en donde el amor cristiano se sostiene como la idea fuerza que engrandece la descripción del emperador, relevaremos de estos poemas los versos referidos a los siguientes atributos (cfr. Whitby, 1998:247-270; 2002:157-173):

» la inspiración divina de Heraclio,

» la influencia que ejerce sobre sus hombres a través del ejemplo,

» el poder persuasivo de su palabra como delegado de Dios,

" los hechos concretos que lo confirman como figura paradigmática cristiana y

" la claridad y serenidad de pensamiento otorgadas por la fe para resolver estratégicamente las situaciones conflictivas.

\section{El poeta}

Jorge de Pisidia procedente de Antioquía de Pisidia (Asia Menor), contemporáneo de Heraclio y del patriarca Sergio, desempeñó diversas funciones de índole administrativa al servicio del patriarca. Fue diácono y archivero de Santa Sofía y, como refendarius, fue el responsable de la comunicación con el emperador. Panegirista reconocido, fue comisionado por Heraclio para que narrara las campañas llevadas a cabo por él (cfr. Russell, 1998:48-49; Howard-Johnston, 2010:17-19; Espejo Jáimez, 2015:66).

He was a voluminous versifier, but his most celebrated compositions were his accounts of Heraclius' campaigns against the Persians and Avars. These poems took the form of encomiastic epic, a kind of composition deriving from, and very popular in, the Hellenistic Age [...] (Romilly; Jenkins, 1963:41).

Su obra no sólo se restringe a la épica encomiástica, destinada principalmente al emperador, sino que también escribe poemas religiosos, otros referidos a la efímera existencia humana y una hermosa alabanza en prosa destinada a San Anastasio, el mártir cristiano.
2. Su importancia es reconocida en el Corán, XXX,I, "Los griegos". Hernández Catá (1883:389). cfr. Ubierna (2000:463-494). 
3. Para el relato histórico de las campañas, cfr. Soto Chica (2012:622740), Mango (2002:55-58)
Sus poemas en general nos revelan a un escritor extraordinario, cuyo elevado estilo delata una gran formación en literatura cristiana y pagana: "He could soften, elongate, and manipulate images with an ingenuity almost unparalleled before or since" (Howard-Johnston, 2010:16). Era un eclesiástico muy consciente de las controversias intelectuales de su época, pero también de la fragilidad humana (cfr. Soto Chica, 2010:224-226).

\section{Contexto histórico}

Heraclio asumió el poder luego de terminar con la tiranía de Focas: "And about the ninth hour of the same Monday, Heraclius was crowned emperor in the most holy Great Church by Sergius, patriarch of Constantinople" (Whitby; Whitby, 2007:152). Era un momento crítico: amenazaban los persas por el este, los ávaros y eslavos por el oeste y reinaba una anarquía total en el imperio ( $c f r$. Cameron, 2006:29). Además, no contaba con recursos pecuniarios ni fuerzas militares organizadas y suficientes.

En este contexto tan adverso tuvo que imponerse como guía sobre una población cuya fe flaqueaba pues veía el avance de las fuerzas paganas como algo inevitable. Ya en el año 614 los persas habían devastado Palestina y asediaban constantemente Jerusalén. Además existían corrientes religiosas que diferían de la doctrina cristiana oficial (cfr. Gregory, 2005:161-162; Rueda, 1997:36-39) y que facilitaban el avance de las hordas persas.

Heraclio reunió y entrenó un ejército disperso en nuevas tácticas militares ( $c f r$. Karantabias, 2005-2006:28-41; Kaegi, 1979:221-227; Ekkebus, 2009:82) $)^{3}$ y participó personalmente en la lucha contra los bárbaros por la reconquista de las tierras en su poder. Internamente inició una organización radical del estado (cfr. Castillo Fasoli, 2009:84) y externamente mantuvo una política ofensiva con la que pudo recuperar gran parte de las ciudades tomadas por los persas. El Imperio Bizantino, que unos años antes de su reinado parecía desaparecer, en el año 628 pudo recuperar el control de Oriente gracias a su valor personal, su determinación y habilidad militar.

\section{Expediciones Pérsicas}

Son tres poemas libremente estructurados en versos yámbicos que narran los preparativos y una de las campañas contra los persas. En un periodo en el cual la historiografía había sido desplazada, estos poemas constituyeron la fuente histórica principal para los estudios posteriores.

The Expeditio Persica is a loosely structured poem in three cantos which heaps praise on Heraclius -merited, the poet insists, not mere flattery- not only for his leadership and sang-froid but even more for his intelligence, clemency, and piety. It is impressionistic, homing in on a small number of episodes with panegyrical potential. There is a fair amount of rhetorical padding, the poet making his presence known throughout (HowardJohnston, 2010:21) (cfr. Espejo Jáimez, 2015:158).

Si bien el poeta secuencia los hechos ordenadamente: la travesía por mar (E.P.I), el entrenamiento de las tropas (E.P.II) y el encuentro decisivo con 
los persas (E.P.III), es de destacar la destreza poética con la que los narra centrándose en la figura del emperador resaltando su fortaleza espiritual y su fe inquebrantable. La elocuencia y las imágenes poéticas que utiliza, así como los personajes bíblicos o de la mitología con los que compara la figura de Heraclio, evidentemente buscan impresionar a un público oyente perteneciente a una elite culta y selecta: "The poem was surely written for public recitation before emperor, and court, probably early in 623" (HowardJohnston, 2010:21).

\section{El amor cristiano de Heraclio}

En Expediciones Pérsicas II Heraclio manifiesta a sus hombres:
4. cfr.Tartaglia (1988:92-94) y Espejo Jáimez (2015:192-193)

\author{
La disposición y el carácter de mi reino \\ me unió a vosotros como a hermanos \\ pues profetizamos que tan grande potestad no \\ brillará en el miedo cuanto en el amor, \\ pues es ley para nosotros contra las violencias humanas, \\ a las que la tiranía armó contra las leyes, \\ que ahora las sustituya la fuerza del amor, / [...]. ${ }^{5}$
}

Su fe sustentada por el amor, lo inspira, lo moviliza, le otorga serenidad y claridad de pensamiento para persuadir a través de la palabra y el testimonio y para resolver las vicisitudes que le presenta la difícil situación del imperio. Plantearemos ordenadamente estas características distintivas.

\section{"Por el retorno desde África del emperador Heraclio y su ascenso al trono y contra el emperador Focas" 6}

Ya el poeta había exaltado el 'tema del amor' inspirado por la fe en este breve poema que data de la primera parte del gobierno de Heraclio, hacia el 611, cuando afirma que su fe se evidencia en el amor que a Dios profesa: "

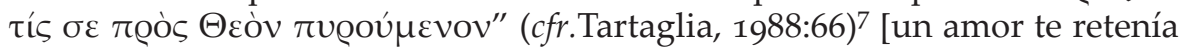
inflamado hacia Dios]. Con anterioridad, más precisamente en el verso 9 había planteado el tema de la 'inspiración divina' como el asunto principal del

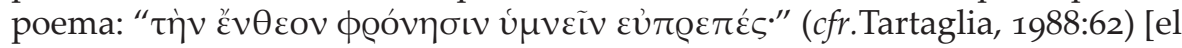
noble pensamiento de inspiración divina (queremos) cantar]. Esta inspiración

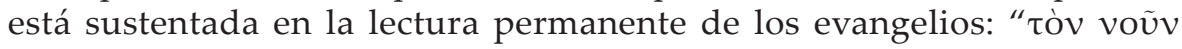

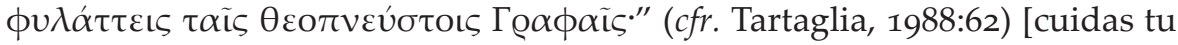
mente con las escrituras inspiradas por Dios].

También Eusebio de Cesarea en la Vida de Constantino hace referencia a este hábito de cobijarse en la reflexión de la lectura de los evangelios:

\section{Para la estructuración del poema, cfr. Espejo Jáimez (2015:146-148).}

7. Para Focas, tiranía y derrocamiento, cfr. Soto Chica (2012:591-625). 
Pruebas aún más nobles que esas podría cualquiera también discernirlas en el ambiente de la iglesia que implantó en el mismo palacio imperial, marcando él personalmente la pauta a cuantos conformaban aquella comunidad ritual: cuando cogía entre sus manos las escrituras, entregaba su espíritu a la meditación de las palabras divinamente inspiradas, después recitaba las oraciones de rigor en compañía de los componentes de la corte (Gurruchaga, 1994:344).

Sus hombres observan la coherencia de sus hábitos y su conducta se convier-

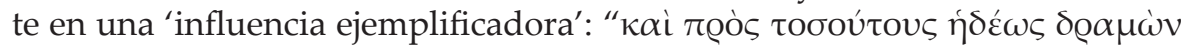

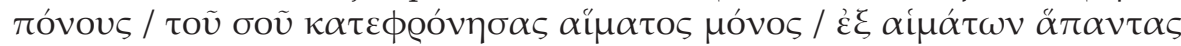

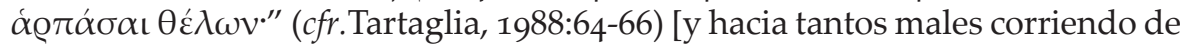
buen grado / único despreciaste tu sangre / queriendo arrebatar a todos de los estragos]. "Lo fascinante de Heraclio es que, al igual que César y Constantino, fue consciente de los pasos que daba, los gestos que exhibía o las palabras, que como en una magistral tragedia, pronunciaba" (Soto Chica, 2005:674).

Con su ejemplo recobra la paz, aleja el mal de la incredulidad y logra la incon-

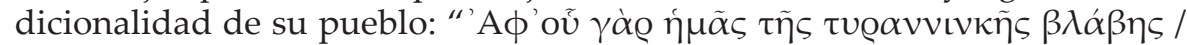

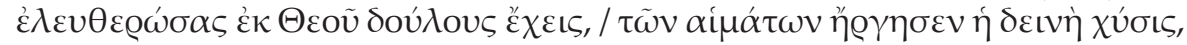

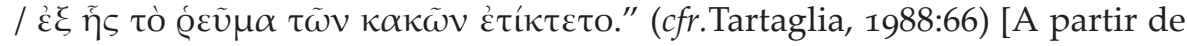
esto, pues, tras liberarnos / del perjuicio tiránico, tienes servidores de parte de Dios, / el terrible derrame de sangres se detuvo, /por el que era generado el flujo de los males.].

Pero también influye con 'el poder persuasivo de su palabra', pues a todos

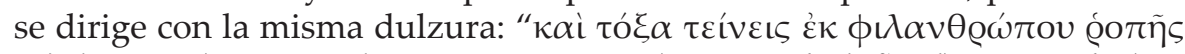

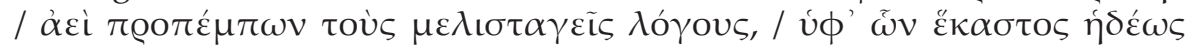

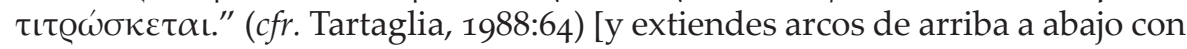
movimiento amoroso / enviando siempre tus palabras que destilan miel, / por las cuales cada uno es herido dulcemente]. La metáfora del arco representa el pensamiento del estratega y las flechas son las palabras persuasivas con las que influye a sus hombres (cfr. Whitby, 1998:259).

Heraclio se presenta ante las tropas participando de la acción a la par de ellos. Utiliza sus 'hechos como testimonio'. El poeta lo compara con Finees, personaje bíblico reconocido por su fe incondicional. Este personaje figura en la Septuaginta. En Números 25: 1-18 se relata la caída de Israel en la idolatría. Las hijas de Moab y Madian, pueblos semitas descendientes de Abraham (cfr. Rahlfs, 1935:36), sedujeron a los israelitas para que compartieran su lecho y el culto al dios Baal. Maldecidos por Dios a través de Moisés. Finees, que en este pasaje ve entrar a uno de sus hermanos israelitas con una mujer madianita, se levantó, se dirigió a su alcoba y mató a ambos sin dudarlo. El personaje queda como paradigma de la fe inquebrantable (cfr. Rahlfs, 1935:261). Un juego etimo-

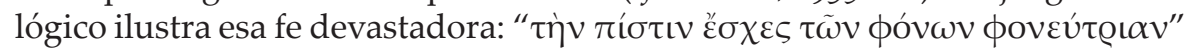
(cfr. Tartaglia, 1988:66) [retuviste la fe masacradora de las masacres].

La fe sustentada en el amor a Dios le da 'Claridad y serenidad de pensamiento'. A través de la negación el poeta elogia estas dos cualidades esenciales. No es a un caballero o a un cazador para quien está destinado el poema, sino para

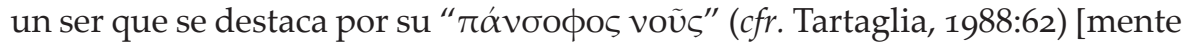

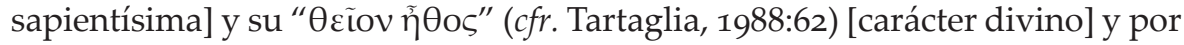

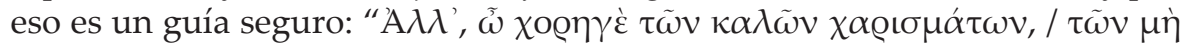

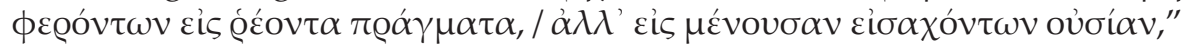
(cfr. Tarataglia, 1988:66) [conductor de bellos carismas / que no llevan hacia hechos inestables / sino que conducen hacia la esencia permanente]. 
El uso de la segunda persona en todo el poema da un tono interpretativo a

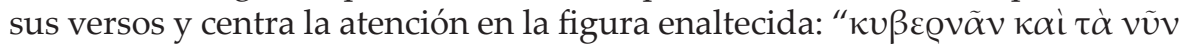

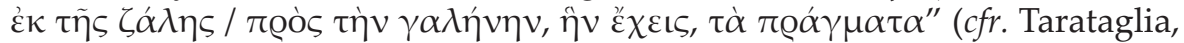
1988:66) [gobiernas desde la tempestad / los actuales acontecimientos, hacia la serenidad que posees].

El poema culmina asegurando que la imagen del emperador quedará resaltada por su 'belleza espiritual' y así quedará grabada en la memoria de los hombres:

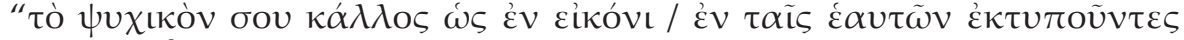
$\kappa \alpha \varrho \delta i ́ \alpha ı \varsigma^{\prime \prime}$ [tu belleza espiritual como en una imagen / tallándola en nuestros

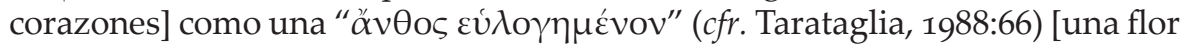
bendecida].

\section{Expediciones Pérsicas ${ }^{9}$}

Tanto el poema anteriormente comentado, como las Expediciones Pérsicas, tenían como destinatario un público cortesano, que estaba al tanto de los logros de su emperador. La habilidad del poeta consiste en la manera poética con la que narra los sucesos enfocándolos de tal modo que siempre queda en primer plano la figura de Heraclio. Comienza invocando a la Trinidad ante el temor

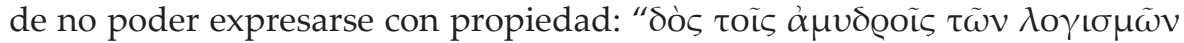

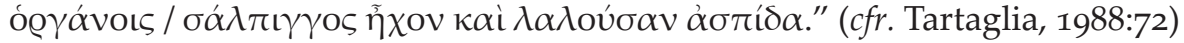
[da a los oscuros instrumentos de mis pensamientos / el eco de la trompeta y el escudo parlante]. Este recurso de la insuficiencia del lenguaje ante la magnitud del tema a tratar es tratado en el manual de retórica de Menandro: “[...] en este tipo de discurso basarás los proemios evidentemente en la amplificación, atribuyéndole grandeza al tema diciendo que es difícil de abordar,[...]" (Gutiérrez Calderón, 1996:146).

Veremos en forma ordenada los atributos detallados al comienzo de este trabajo:

1. la inspiración divina: En E.P.I una proporción importante de versos está destinada a describir lo que en la corte se opinaba respecto de la resolución del emperador. El hecho de que este participara personalmente en las campañas ya no era común. Sin embargo, él, sostenido por la fe, tomaba como único juez

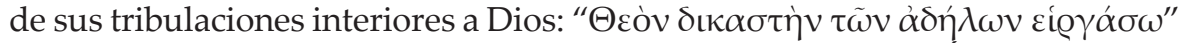
(cfr. Tartaglia, 1988:80) [hiciste a Dios juez de lo no manifiesto]. El estaba seguro de que Dios le indicaba el camino y que el resto solo entendería la integridad

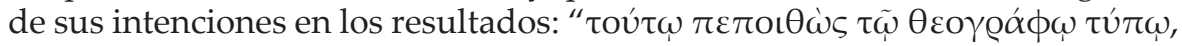

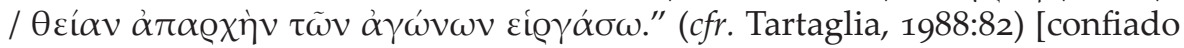
en este modelo escrito por Dios, / hiciste la divina primicia de las luchas]. En la Vida de Constantino leemos al respecto:

Era lento, para asegurarse más, y pensaba que todo había de hacerse con el designio de Dios. En el tiempo que dedicaba a Dios, mientras hacía sus oraciones, siempre obtenía una aparición divina, entonces como impelido por una ración deífica, saltando súbito fuera de su tienda, ordenaba a las tropas movilizarse inmediatamente, y que sin dudarlo echaran mano al instante a sus espadas (Gurruchaga, 1994:217).

Ajeno a la desmesura de los rituales de los bárbaros impíos, afianza su fe inspiradora con la lectura de las Sagradas Escrituras. Esto se destaca en E.P.II:
8. Este mismo verso encontramos en Expediciones Pérsicas | 121. 


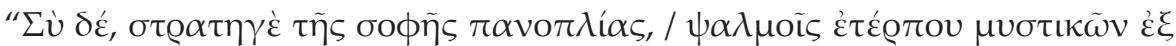

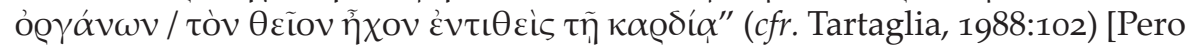
tú, Estratega de la sabia armadura, te deleitabas con salmos de místicos instrumentos / poniendo el divino eco en tu corazón].

2. La influencia ejemplificadora: En E.P.I el poeta narra la travesía por mar y el temporal, que deben enfrentar, es espejo de la realidad adversa con la que tiene que lidiar constantemente Heraclio: " $\phi \theta \alpha \dot{\alpha} \nu \omega v \varepsilon \varepsilon \kappa \alpha ́ \sigma \tau \eta v ~ \sigma v \mu \phi о \varrho \tilde{v} \tau \varrho \iota \kappa v \mu i ́ \alpha \nu$

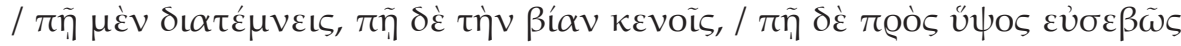

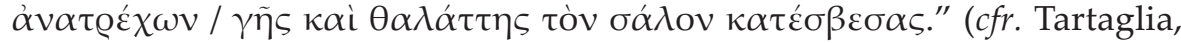
1988:86) [adelantandote a cada oleada de desgracias / en parte la disuelves, en parte neutralizas la violencia, / pero en parte elevándote piadoso / hacia lo sublime / apaciguaste la agitación de la tierra y el mar].

Durante la tormenta una nave encalla entre las rocas y el estratega acude en

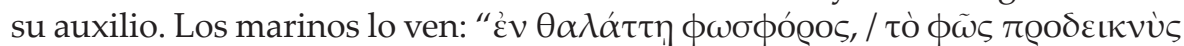

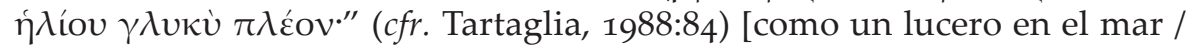
mostrando la luz más dulce que el sol]. Es oportuno aclarar que la representación del soberano como si fuera un sol, es un tópico recurrente que pode-

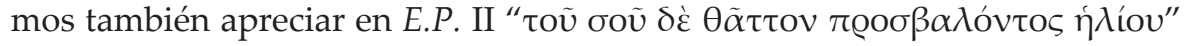
(cfr. Tartaglia, 1988:104) [pero al aparecer muy veloz tu luz solar]; E.P. III

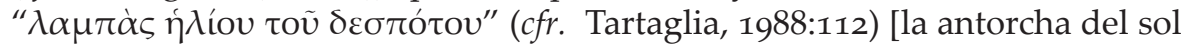

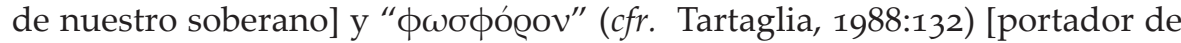
luz]. Menandro se refiere a este tópico, cuando aconseja tenerlo presente en el proemio: "[...] luego has de añadir: 'cuando la noche y la oscuridad se habían adueñado de todo, tú, apareciendo como un sol, disipaste todas las dificultades a la vez"' (Gutiérrez Calderón, 1996:163).

Ellos observan, además, cómo expone su propia vida para rescatar la nave

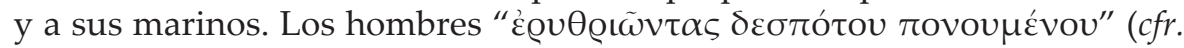
Tartaglia, 1988:84) [avergonzándose porque su señor peligraba], siguen su ejemplo y se esfuerzan aún más para salvar a sus compañeros.

Al comienzo de E.P.II y antes del entrenamiento de las tropas, el poeta juega con preguntas y respuestas para resaltar el valor paradigmático del empe-

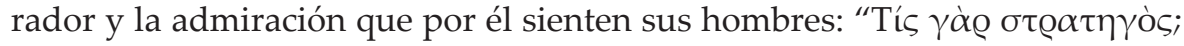

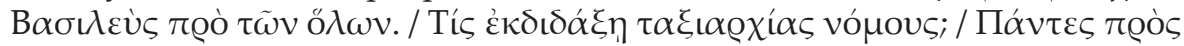

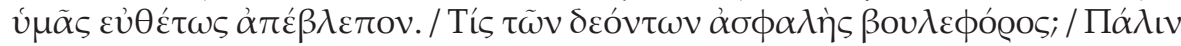

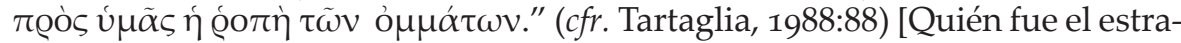
tega? El soberano delante de todos. / ¿Quién enseñó las leyes de la estrategia? / Todos hacia ti observaban en buen orden. / ¿Quién fue seguro consejero de las cosas convenientes? / Otra vez hacia ti el movimiento de los rostros.].

Esta manera de presentarlo genera la sensación de asistir a una escena, en donde Heraclio es la estampa viviente, el poeta, el orador y los hombres alternativamente y en silencio miran a uno y a otro.

En E.P.III ya en la lucha, Heraclio enfrentaba esta amenaza buscando preservar la seguridad de sus hombres y esta actitud ejemplar los incentiva a luchar con más empeño:

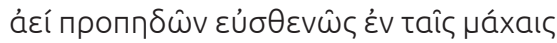

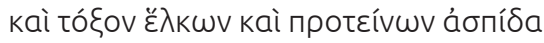

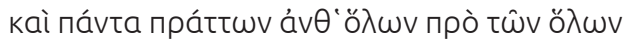

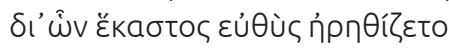




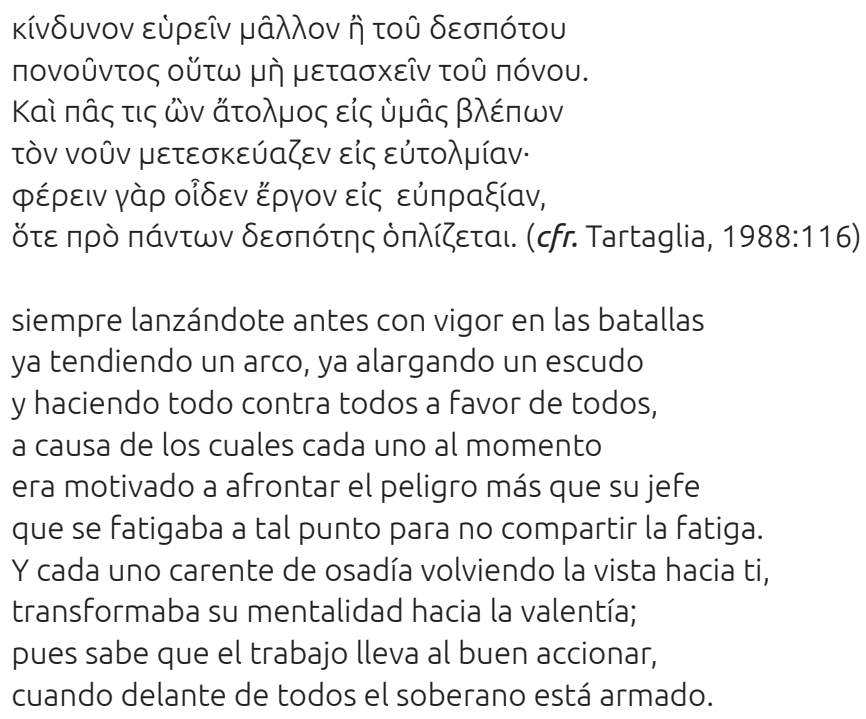

Mediante el recurso de la acumulación, el juego de palabras ('haciendo todo contra todos a favor de todos' o 'se fatigaba a tal punto para no compartir la fatiga') y el uso del imperfecto, el autor logra dar a la escena un aspecto durativo, como si se tratara de una cámara lenta que lleva a un primer plano la figura heroica de Heraclio en un despliegue sobrehumano de valor, capaz de arriesgar su vida por sus hombres. El uso del presente, "oĩ $\delta \varepsilon v$ ", da un carácter de sentencia a los dos últimos versos y resalta aún más la ejemplaridad del estratega.

3. El poder persuasivo de la palabra: En los primeros versos de E.P.I encontramos en un vocativo la cualidad principal del emperador consejos: " $\mathrm{A} \lambda \lambda$ ',

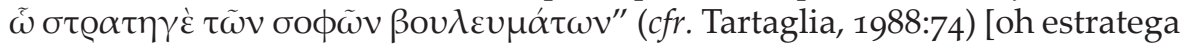
de los sabios]. Luego es comparado con Néstor por la dulce elocuencia de sus parlamentos:

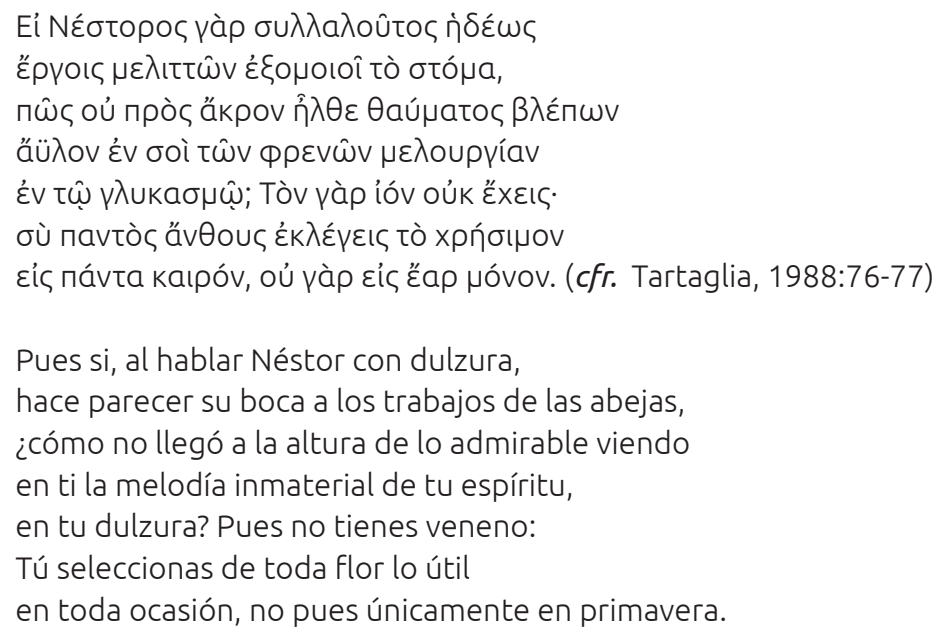

El poeta destaca la capacidad de Heraclio para cuidar el efecto de sus palabras de modo de influir a través de la benevolencia y la afabilidad, en lugar del inflexible autoritarismo y, como la abeja que busca el mejor polen para elaborar la miel, él selecciona con cuidado sus palabras para persuadir.

Observamos el mismo motivo en E.P.II, donde lo describe como un intérprete consciente de la voluntad divina que imprime en sus parlamentos la 
bondadosa dulzura de las palabras, convencido de llegar primero a los cora-

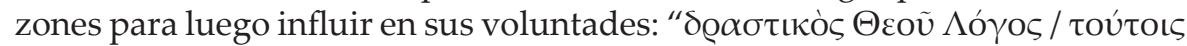

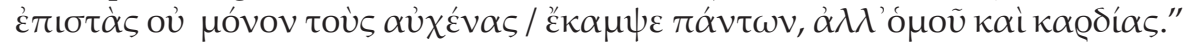
(cfr. Tartaglia, 1988:92) [la palabra enérgica de Dios / al imponerse sobre ellos no únicamente doblegó los cuellos / de todos, sino de modo semejante también sus corazones]. De este modo, pudo reorganizar el ejército disperso y modifi-

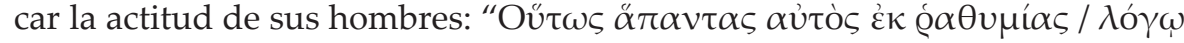

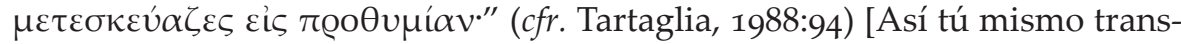
formabas con la palabra / a todos desde la indolencia hacia la laboriosidad].

Incluso en los momentos críticos del enfrentamiento con los persas en E.P.III, el estratega organiza a sus tropas con las palabras apropiadas: "K $\alpha \mathrm{i}$

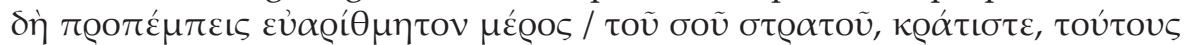

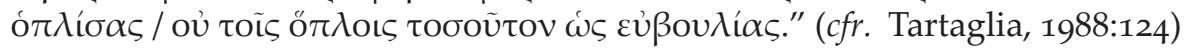
[Y envías por cierto una parte poco numerosa / de tu ejército, Soberano, tras armar a estos / no tanto con las armas cuanto con buenos consejos].

4. Los hechos como testimonio: En E.P.I durante la tempestad Heraclio pone tal empeño en la tarea de auxiliar a sus hombres, que moviliza a estos

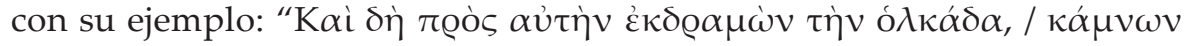

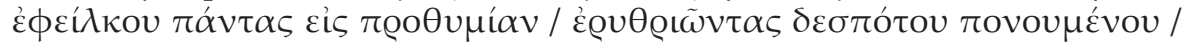

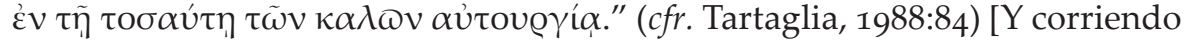
hacia esa misma nave, / trabajando arrastrabas a todos hacia la diligencia / avergonzándose porque su Señor peligraba / en tamaño esfuerzo personal de nobles acciones].

En E.P.II el poeta destaca la misma actitud consecuente que le permite resolver

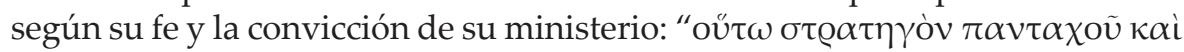

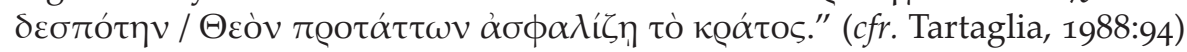
[así anteponiendo a Dios como estratega y señor por todas partes / consolidas el poder]. Hechos concretos que despiertan la admiración de todos, pues

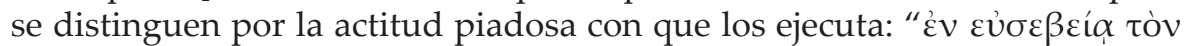

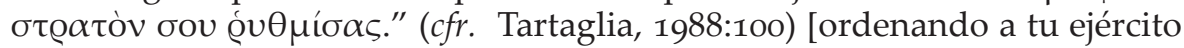
con la piedad].

En E.P.III durante el encuentro decisivo con los persas, el poeta nos describe a un táctico sereno, seguro de sí, que transmite orden y estabilidad a sus tropas y esta visión paraliza al bárbaro, que desde el monte observa el avance de las tropas.

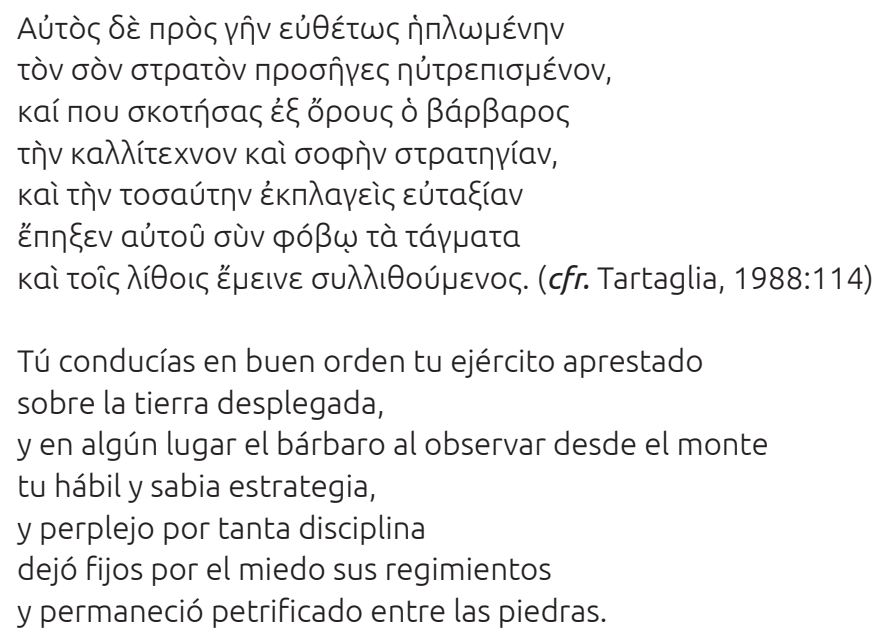


En la Crónica de Teófanes Confesor, una de las mayores fuentes del Oriente romano, se detalla este enfrentamiento de Heraclio con los persas con minucioso detalle. Lo que en la poesía de Jorge de Pisidia parece parte de una descripción pintoresca del terreno, observamos en la crónica que se vincula estrechamente con una estrategia propia del bárbaro, que consistía en atacar por sorpresa y regresar a las montañas a la espera de otra oportunidad. Vale la pena la lectura de un fragmento:

\begin{abstract}
Fearing (Sarbaros), however, lest the emperor invade Persia by way of Armenia and cause disturbance therein, he could not make up his mind what do do. Even so, he was compelled to follow the Roman army from behind, seeking a chance to steal a fight and attack them on a dark night. But there was that night a full moon and he was foiled in his scheme and uttered imprecations against the moon whom he had previously worshipped; and it so happened that the moon suffered an eclipse that night. Because of this, Sarbaros was afraid to attack the emperor and he made for the mountains as the deer do, and observed from a height the beautifully ordered generalship of the Romans. When the emperor became aware of his cowardice, he boldly encamped in places affording ample repose and provoked him to war. Often the Persians would come secretly down from the mountains and engage in sporadic conflict, and on all occasions the Romans had the upper hand and their army was further emboldened by seeing the emperor dashing forward in front of all the others and fighting courageously. (Mango; Scott, 1997:436-437).
\end{abstract}

5. Claridad y serenidad de pensamiento: La fuerza inspiradora de la fe le permite a Heraclio encarar tanto los problemas internos del imperio, como la amenaza constante de los pueblos bárbaros, con la serenidad y claridad propias de un ser especial. Esto le confiere, además, un profundo sentimiento de alteridad que le permite un trato amable con sus hombres y piadoso con los suyos y el enemigo. El poeta busca resaltar estas condiciones especiales en los tres poemas y aprovecha los sucesos que narra para destacarlas. Así, por

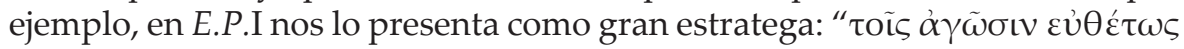

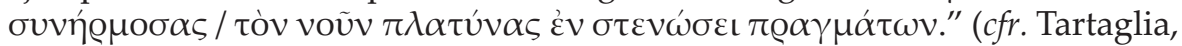
1988:74) [en las batallas conciliaste en buen orden / ampliando tu mente en la estrechez de los acontecimientos]. En E.P.II se nos describen las condiciones en las que se hallaban las tropas antes de asumir Heraclio: desordenadas, dispersas por distintas regiones del imperio y con diversidad de etnias y lenguas que dificultaban la reorganización. El poeta rescata la gran capacidad del

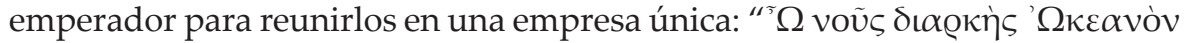

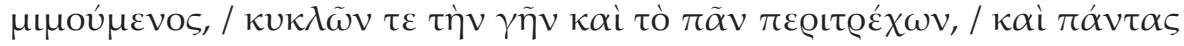

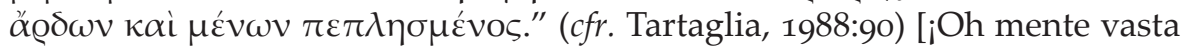
que representa el océano / rodeando la tierra y recorriendo todo, / reanimando a todos y permaneciendo colmado!].

Con serenidad aplica la clemencia con el enemigo, pues vislumbra el triunfo de la fe cristiana sobre estos pueblos y la restauración del imperio: "A $\lambda \lambda$ 'oủ $\delta \dot{\varepsilon}$

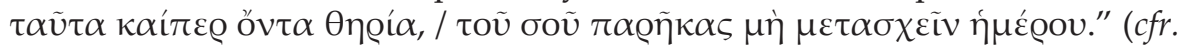
Tartaglia, 1988:100) [Pero ni con esta (raza), a pesar de ser fieras, / descuidaste tu clemencia para no compartirla] (cfr. Whitby, 1998:260).

En E.P.III la claridad y serenidad del estratega se manifiesta en sus movimientos tácticos pues con hábiles maniobras encierra a los persas en un lugar escarpado (cfr. Gutiérrez Calderón, 1996:156). Imágenes marinas

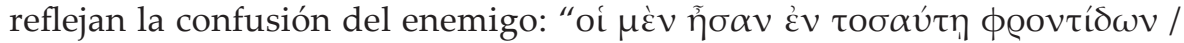

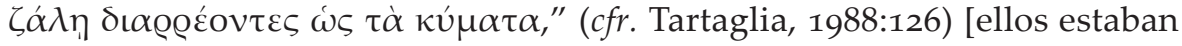


10. Sobre esto ver nota 4 de este trabajo, donde resaltamos los versos que tratan sobre el tópico literario de comparar al soberano con el sol. en tal tempestad / de preocupaciones, esparciéndose como las olas], "oú $\tau \omega \varsigma$

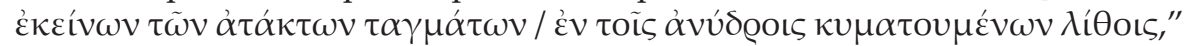
(cfr. Tartaglia, 1988:126) [así agitándose aquellos regimientos desordenados / entre las rocas sin agua]. En contraste, las tropas romanas mantienen el orden y la calma.

\section{Conclusión}

Según Mary Whitby en el siglo VII los recursos propios del panegírico imperial ya estaban estandarizados y esto permitió a Jorge de Pisidia explotarlos en función de enaltecer la figura de Heraclio para sostener la estabilidad de su gobierno y la aceptación de sus súbditos, a pesar de sus prolongadas ausencias a causa de las campañas que lo alejaban de la capital (cfr. Whitby, 1998:270). La misma opinión comparte Kaegi:

Heraclius and his panegyrists compared Heraclius with David, with Moses, and with Constantine I. They celebrated his many virtues, including his mental and physical versatility, his mildness and clemency, and sought to keep him, while absent from Constantinople on campaign or other missions, reassuringly in the minds of Constantinopolitans. (Kaegy, 2004:301).

Al comienzo de nuestra comunicación comentamos que Heraclio había comisionado a Jorge de Pisidia para que narrara sus campañas contra Persia. Ambos no hacían más que continuar con la tradición de la oratoria epidíctica, cuya intencionalidad específica era fundamentalmente propagandística. La mayor parte de la obra de este autor estaba destinada principalmente a la corte y a un público letrado de cuya aprobación dependía el emperador para su estabilidad institucional (cfr. Lauxterman, 2003:56). Destacamos también parte del discurso que Heraclio dirige a sus hombres en E.P.II, donde asegura que su poder estará cimentado en el amor. Un sentimiento inspirado por la fe que lo guiará en sus actitudes y decisiones y que se manifestará en hechos concretos y acciones ejemplares. El poeta, centrado en este principal atributo, narra los hechos y describe las cualidades del emperador reiterando este pensamiento como idea recurrente. Asegura que sus hombres conciben su presencia como un ser luminoso ${ }^{10}$ que los reúne en un sentimiento común y así superar los límites raciales y lingüísticos que le permiten seguirlo. En E.P.II se refiere a este sentimiento

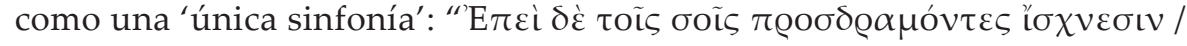

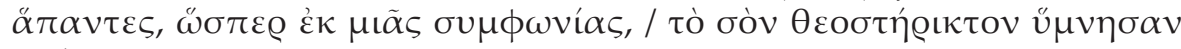

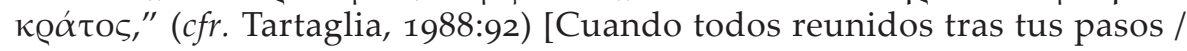
como en una única sinfonía, / elevaron un himno a tu poder sostenido por la divinidad]. En E.P.II (cfr. Tartaglia, 1988:100) es comparado con un "sabio médico" que sana las enfermedades del cuerpo del ejército, en E.P.I (cfr. Tartaglia, 1988:86) es el gran marino que gobierna los timones de la vida y

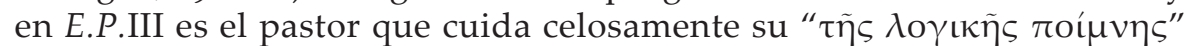

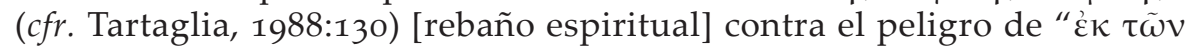

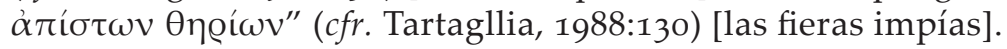

El logro de Jorge de Pisidia en este panegírico es haber retratado las cualidades propias del líder bizantino pincelando cada una de ellas con la especial visión del amor cristiano, como la fuerza motora de sus acciones. De este modo, logra renovar en la figura de su mecenas los principios básicos de la política bizantina. El emperador es el fundamento divino que afianza la monarquía 
sobre cualquier otra forma de gobierno y el imperio representa la comunidad cristiana. En E.P.II el poeta hace referencia a esto: " $\Omega \varsigma \varepsilon \tilde{v} \kappa \rho \alpha \tau o \tilde{v} \sigma \alpha \sigma \dot{v} v \Theta \varepsilon \tilde{\omega}$

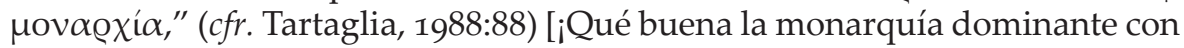
la compañía de Dios!].

Cuánto hay de verdadero o sólo se trata de un recurso más del que hábilmente se valió el poeta para hacer la diferencia, nos queda como interrogante. Según Kaegi, la vida de Heraclio no fue fácil y hubo de soportar adversidades de todo tipo, enfrentamientos civiles, asedio de pueblos bárbaros, divergencias religiosas, muerte de seres queridos y, finalmente, la soledad (cfr. Kaegi, 2004:300). Según Soto Chica, Heraclio era consciente de la influencia que ejercía sobre sus hombres y por eso no descuidaba ningún detalle, ni de su imagen ni de sus acciones, pero esto no era algo artificial, sino que realmente lo sentía. Por eso, "no hay nada sesgado, artificial, falso o casual en las 'acciones heroicas' de Heraclio entre 622 y 630" (cfr. Soto Chica, 2005:674; Whitby, 1998:261; Soto Chica, 2012:677; 683-686). La distancia temporal nos desdibuja la intención final, pero creemos que semejante personalidad no sólo fue guiada por el ansia de poder y que su férrea voluntad fue sostenida por una profunda convicción espiritual. 


\section{Q Bibliografía}

" Brandes, W. (2002). "Heraclius between restoration and reform. Some remarks on recent research". En: Reinink, J.; Stolte, B. (eds), The Reign of Heraclius (610-641): Crisis and Confrontation. Leuven: Peeters, 18-40.

» Castillo Fasoli, R.D. (2009). Historia breve de Bizancio. Madrid: Sílex.

"Ekkebus, B. (2009). "Heraclius and the Evolution of Byzantine Strategy", Constructing the Past 10, 73-96. En: http://digital commons.iwu.edu/constructing/vol10/iss1/11; obtenido el 08/08/2018.

»Espejo Jáimez, G. (2015). Significación literaria e ideológica en la tradición bizantina de los Panegíricos Épicos de Jorge de Pisidia. Granada: Universidad de Granada.

» Fogginus, P.F. (ed.) (1777). Corporis Historiae Byzantinae. Nova Appendix. Opera Georgii Pisidae Theodosii Diaconi et Corippi Africani Grammatici. Roma: Benedictum Francesium.

" Gómez, H.; Brenates, F. (eds.) (2004). Vasiliev, A. Historia del imperio bizantino. Soporte electrónico Http://www.imperiobizantino.com. Rolando Castillo. España: Madrid.

» Gregory, T.E. (2005). A History of Byzantium. Malden: Blackwell.

» Gurruchaga, M. (trad.) (1994). Eusebio de Cesarea. Vida de Constantino. Madrid: Gredos.

» Gutiérrez Calderón, J. (1996). Menandro el Rétor. Dos tratados de Retórica Epidíctica. Madrid: Gredos.

" Haldon, J. (2002). "The reign of Heraclius a context for change?". En: Reinink, J.; Stolte, B. (eds), The Reign of Heraclius (610-641): Crisis and Confrontation. Leuven: Peeters, 1-16.

» Hernández Catá, A. (trad.) (1883): Mahoma. Corán. Paris: Garnier.

» Howard-Johnston, J. (2010). Witneses to a World Crisis. Historians and Histories of the Middle East in the Seventh Century. New York: Oxford University Press.

" Kaegi, W. (1979). "Two notes on Heraclius". Revue des études byzantines 37, 221-227.

» Kaegi, W. (2004). Heraclius. Emperor of Byzantium.Cambridge: Cambridge University Press.

" Karantabias, M.A. (2005-2006). "The Crucial Development of Heavy Cavalry under Herakleios and His Usage of Steppe Nomad Tactics". Hirundo 4, 28-41.

» Laurent, V. (1939). "Notes de titulature byzantine", Échos d'Orient 195-196, 355-370.

"Lauxtermann, M. (2003). Byzantine Poetry from Pisides to Geometres. Textes and contexts. Wien: Akademie der Wissenschaften.

» López Cruces, J.; Papadopoulou, P. (eds.) (2017). Sánchez Egea, J. La lengua Griega Medieval. Granada: CBNCh.

» Mango, C. (ed.) (2002). The Oxford History of Byzantium. New York: Oxford University Press.

" Mango, C.; Scott, R. (trad.) (1997). The Chronicle of Theophanes Confessor. Byzantine and Near Eastern History AD 284-813. New York: Oxford University Press. 
" McGuckin, J. (2011-2012). "A Conflicted Heritage: The Byzantine Religious stablishment of a War Ethic", DOP 65/66, 29-44

» Pertusi, A. (ed. y trad.) (1959). Giorgio Di Pisidia. Poemi. I Panegirici Epici. Ettal: BuchKunstverlag.

"Queiroz de Souza, G. (2015). "Heraclius, Emperor of Byzantium”, Revista Digital de Iconografía Medieval, 14, 27-38.

»Rahlfs, A., (ed.) (1935). Septuaginta. Germany: Württembergische Bibelanstalt Stuttgart, Tomo I.

" Regan, G. (2001). First Crusader.Byzantium's Holy Wars. Sparkford: Sutton Publishing Limited Phoenix Mill.

» Riveros, J. (2011). "Bizancio en el siglo VII: Entre Historia y Profecía. Notas en torno a sus sucesos del año 626", BNH30, 41-73.

" Romilly, J.; Jenkins, H. (1963). "The Hellenistic of Byzantine Literature", DOP 17, 3952.

» Russell, D. (1998). "The Panegyrists and their Teachers". En: Whitby, M. (ed.), The propaganda of power. The role of Panegyric in Late Antiquity. Leiden - Boston - Koln: Brill, 15-50.

"Serrano del Pozo, J. (2018). "El emperador Heraclio (610-641) entre la historia y la leyenda: un estado de cuestión", Intus-Legere Historia 12, 87-113.

» Soto Chica, J. (2005). "La política heroica de Heraclio. Un puente entre el héroe grecorromano y el caballero cristiano 619 a 630", CEBNCh. Navarra: Euskal Herriko Unibertsitatea, 671-684.

"Soto Chica, J. (2010) Bizantinos, sasanidas y musulmanes. El fin del mundo antiguo y el inicio de la Edad Media en Oriente. 565-642. Granada: Universidad de Granada.

"Soto Chica, J. (2017). "Héroes mitológicos y héroes bizantinos. Mitología griega y orígenes del caballero cristiano Bizantino en los procesos de heroificación de Juan Troglita, Belisario y Heraclio (530-630). En: Alganza Roldán, M.; Papadopoulou, P. (coords.), La mitología griega en la tradición literaria: de la Antigüedad a la Grecia contemporánea. Granada: Centro de Estudios Bizantinos, Neogriegos y Chipriotas, 247-264.

» Tartaglia, L. (trad.) (1988). Carmi di Giorgio di Pisidia. Torino: Unione Tipografico Editrice Torinese.

"Whitby, M. (1998). "Defender of the Cross: George of Pisidia on the Emperor Heraclius and his deputies". En: Whitby, M. (ed.), The propaganda of power. The role of Panegyric in Late Antiquity. Leiden - Boston - Koln: Brill, 246-270.

"Whitby, M. (2003). "George of Pisidia's presentation of the emperor Heraclius and his campaigns. Variety and Development". En: Reinink, J.; Stolte, B. (eds), The Reign of Heraclius (610-641): Crisis and Confrontation. Leuven: Peeters, 157-173.

"Whitby, M.; Whitby, M. (trads.) (2007). Chronicon Paschale 284-628 AD. Liverpool: Liverpool University Press. 
